\title{
Problems in the Industrial Use of Electrodeposited Alloy Golds
}

\author{
CONSIDERATIONS OF CONTROL AND OF \\ RESISTANCE TO CORROSION
}

\section{R. Mason}

Engelhard Industries Limited, Cinderford, Gloucestershire, England

\begin{abstract}
Economic considerations have recently focused attention on the possibility of using the decorative type of alloy gold plating in industrial applications. In this article the author reports on an investigation into the performance of a number of alloy golds and concludes that they have serious shortcomings in terms of resistance to corrosion, while the additional cost of controlling the electrolytes tends to offset any savings effected.
\end{abstract}

For many years the electrodeposition of alloy golds has been practised successfully in the decorative fields, where appearance is of course of greater importance than the performance of the deposit in terms of its electrical properties and hardness. Most of these alloy deposits contain from about 65 to 75 per cent gold, and for obvious reasons suggestions have been made for their appraisal with a view to their specification and use in industrial applications where pure or almost pure gold is generally employed.

In a paper recently presented to the Institute of Metal Finishing at its Annual Conference the author and two of his colleagues (1) described an investigation of a number of alloy gold electrolytes from this point of view-that is for their acceptability in the industrial field. Deposits from these electrolytes were evaluated for resistance to corrosion, internal stress, hardness and wear resistance and solderability.

\section{Alloy Gold Systems}

The selection of a metal or metals for co-deposition with gold is a significant factor. They should not only be capable of readily co-depositing with the gold but also of offering appreciable resistance to oxidising conditions. Unfortunately the former is the deciding factor, as most chemically stable metals will not alloy with gold and will produce highly stressed deposits. The possible alloy combinations can be listed as follows:

\section{Gold-Copper-Cadmium}

This deposit is generally obtained from an alkaline cyanide electrolyte. A quaternary $\mathrm{Au}-\mathrm{Cu}-\mathrm{Cd}-\mathrm{Ag}$ system has also been proposed, but the additional degree of control for such "multi-metal" electrolytes poses severe production problems. Clearly, the more constituent metals that are present in a solution the greater is the skill required to maintain the process-a difficulty compounded by the presence of brightening agents and special buffering additives in some versions of these systems. Gold, cadmium and copper are all strongly complexed by the cyanide ion, and the amount of metal available for deposition is determined by its stability constant and by the free cyanide concentration. This type of electrolyte has, however, been the mainstay of colour gilding, and its effectiveness in this field is the result of long experience in operating a process where the slightest variation in $\mathrm{KCN}$ concentration or in $\mathrm{pH}$ brings about a noticeable colour change in the deposit. A typical deposit composition would be 75 per cent gold, 15 per cent copper and 10 per cent cadmium, but a small change in the low cadmium content brings about a relatively large change in the characteristics of the deposit and the bath must therefore be managed with great care and control.

\section{Gold-Silver}

Alkaline cyanide electrolytes giving a gold-silver alloy deposit are well known, producing fully bright deposits ranging down to 50 to 60 per cent gold, but again close control of cyanide and silver contents are required in order to obtain consistent results, while the degree of agitation also has a marked effect on the composition of the deposits, which are generally highly stressed and of poor resistance to corrosion. 


\section{Gold-Copper-Antimony}

Acid or neutral cyanide electrolytes allow a wider range of metals to be co-deposited, and a number of processes has been put forward on this basis. The most frequently recommended bath is a gold-copper system with 1 or 2 per cent of a third metal such as antimony, arsenic, bismuth or lead. These are capable of producing bright and hard depcsits, but again will maintain this standard only in the hands of a skilled and experienced operator, while the corrosion resistance is not of an industrial standard. As deposited, discrete areas of copper are present which will tarnish heavily, and only after a heat treatment at 300 to $400^{\circ} \mathrm{C}$ is the deposit truly alloyed and resistant to corrosion.

\section{Gold-Cadmium}

A gold-cadmium electrolyte based upon gold sulphite has shown promise in the decorative field. Its internal stress is, however, high and its resistance to corrosion only moderate, while the sulphite bath requires more attention than cyanide electrolytes. A deposit of 80 to 90 per cent gold is obtained, but as a group the alkaline sulphite solutions, appear to show least promise for industrial purposes.

\section{Gold-Copper}

From an acid or neutral sulphite electrolyte it is easier to introduce base metals into the deposit than from an alkaline sulphite bath, and the principal system here is based upon gold-copper, the most successful being a 66 per cent gold 34 per cent copper alloy which is bright, of low stress, and has good solderability. Its resistance to corrosion is, however, only moderate, while the stability of the bath tends to fall off as the solution is worked.

\section{Properties and Applications}

From the results of extensive hardness, corrosion, wear and solderability tests, reported fully in the original paper (1), an assessment was made of the possible suitability of these alloy golds for use in the major types of applications in the electrical and electronics industry.

\section{Semiconductors}

The gold plating of transistor headers and lead frames generally calls for a pure gold deposit, although sometimes a trace amount of alloying element such as arsenic or antimony is permitted. A heating operation is involved, and ease of die-bonding is important. It seems quite unlikely that alloy golds will be used in this area on this account, while the barrel plating or selective plating of alloy golds would introduce considerable problems, particularly in controlling the composition of the deposit.

\section{Contacts}

In contact applications such as edge connectors and the like the majority of the alloy gold deposits investigated would be suspect on the grounds of resistance to tarnish and corrosion. The only system that might be found acceptable would be the goldcopper-cadmium alkaline cyanide electrolyte, which showed a wear resistance a little superior to that of conventional pure gold deposits, although it showed some discolouration when corrosion tested in an $\mathrm{SO}_{2}$ atmosphere.

\section{Printed Circuits}

The accepted maximum hardness value for gold deposits on printed circuits-normally plated from either a neutral or an acid pure gold-is $150 \mathrm{Hv}$. All the alloy gold deposits gave hardness figures greatly in excess of this, ranging from 270 to $420 \mathrm{Hv}$, and none would thus be acceptable unless specifications were radically changed.

\section{Conclusions}

From the results obtained with the wide range of processes evaluated it is reasonably clear that none of the alloy golds provided an equivalent corrosion resistance to current industrial gold electrolytes, although this situation could conceivably be improved by more selective pre- or post-plating treatments. For example, if the total thickness of deposit cannot be achieved with an alloy gold, a duplex system involving over-plating the alloy with a pure gold deposit would enable some saving to be effected.

Thus alloy gold deposits may have a part to play in the industrial field, but the selection of the system to be adopted must be made after careful consideration of the properties required in the deposit and of the effect of the electrolyte on the components to be plated. Furthermore, before the use of alloy gold deposits could become general, specifications would have to change; if deposit hardnesses in the region of 300 to $400 \mathrm{Hv}$ are to be accepted it will be necessary to establish a relationship between hardness, ductility and strength in order to avoid the use of brittle deposits.

Considerably more control is required, however, in working with alloy gold electrolytes. Apart from regular analysis of the bath constituents, the operating parameters-temperature, current density, $\mathrm{pH}$ and agitation-all affect the composition of the deposit and require close attention. The additional cost of control must therefore be set against any expected reduction in metal cost before an overall saving is obtained.

\section{Reference}

D. R. Mason, A. Blair and P. Wilkinson, Trans. Inst, Metal Finishing, 1974, in the press 